\title{
The Affordability of Natural Gas Price in China: A Literature Review
}

\author{
Xutao Rui* \\ School of Business Administration \\ China University of Petroleum \\ PetroChina Planning and Engineering Institute \\ Beijing China \\ ruixutao@petrochina.com.cn
}

\author{
Lianyong Feng \\ School of Business Administration \\ China University of Petroleum \\ Beijing, China
}

\begin{abstract}
Natural gas price affordability reflects natural gas users willingness to pay for natural gas, and its price form is characterized by affordable natural gas prices. Unlike market prices, affordable natural gas prices cannot be quantified through market supply and demand relationships, and they reflect the highest price a user can afford to purchase natural gas. For the study of natural gas price affordability, chinese scholars have established the theory of natural gas price affordability system. This paper summarizes the chinese natural gas price a affordability literature, and systematically sorts out the theoretical system of natural gas price affordability, and proposes the main directions of future research and development.
\end{abstract}

Keywords-China; Natural gas; Affordability; Affordable price

\section{INTRODUCTION}

Natural gas price affordability reflects natural gas users willingness to pay for natural gas, and its price form is characterized by affordable natural gas prices. Unlike market prices, affordable natural gas prices cannot be quantified through market supply and demand relationships, and they reflect the highest price a user can afford to purchase natural gas. There is still a blank in the literature review on the research of China's natural gas price affordability. Therefore, this paper summarizes the literature on China's natural gas price affordability, proposes the main direction of future research and development, and proposes to further improve the theoretical system and research direction of China's natural gas price affordability.

\section{DEFINITION OF NATURAL GAS MARKET VALUE}

For the natural gas market value, Chinese scholars have defined them from different angles.

Bai Lanjun [1-2] put forward the concept of "economic value of natural gas" and clarified gas price is "determined by the lowest price of alternative energy". The West-East Gas Transmission Research Group [3] put forward the concept of "natural gas market value". It is believed that the market value of natural gas is usually determined based on the price of competitive fuel, or it is determined by reference to the price of natural gas from other sources. Wang Guoliang et al. [4] pointed out that the market value of natural gas refers to the price of the same cost when user replaces other fuels with natural gas, which takes into account the difference in calorific value of different fuels, the difference in heat utilization efficiency, and the use of different Fuel investment and use costs and final pollution costs, etc. Hao Yu et al [5], Hong Bo et al [6] believe that the value of natural gas market is the highest price that natural gas users can use to meet certain functional needs, that is, 'the natural gas market can bear the price". Li Luguang et al. [7] proposed the concept of "natural gas use value" and "economic value of natural gas use", and concluded that natural gas use value is a function that can be satisfied by the natural properties of natural gas to meet the needs of related use. The economic value of natural gas use is The economic value achieved through the use of natural gas."

Different scholars have defined the value of the natural gas market from different angles. By summarizing the definition, it can be known that: First, the natural gas market value reflects the user's ability to withstand the natural gas market price, and its price form is characterized by affordable natural gas prices when it can withstand natural gas. IF the price is higher than the market price, the user chooses to consume natural gas, and if lower than the market price, the user gives up the consumption of natural gas, or chooses to consume other energy. Second, the price of affordable natural gas is different from the market price and cannot be determined by the relationship between market supply and demand. It is equivalent to the concept of reserve price in economics. It is the consumer's willingness to accept and purchase the highest price of the relevant goods. The product cost, the market supply price of the product and the user's profitability or the alternative energy price level are the price of the natural gas market value.

\section{CALCULATION METHOD OF AFFORDABLE NATURAL GAS PRICES}

As for the calculation of affordable natural gas price, the commonly used methods in China include alternative energy price method, net return value method, statistical analysis method, expenditure limit method, input-output method and so on.

\section{A. Alternative Energy Price Method}

The alternative energy price method is a method to determine the affordable natural gas price according to the principle of effective calorific value equivalence and the energy price which has the alternative competition relationship 
with natural gas. Chinese scholars generally use this method to calculate the affordable natural gas price [4,8-15]. Under the premise of known alternative energy price, natural gas calorific value and alternative energy calorific value, the affordable natural gas price can be obtained quickly, but there are great deviations in the application process. Therefore, Li Luguang et al. [7,16-17] based on the principle of unit effective calorific value equivalence, introduced the basic principles of technical economics, took the project as the evaluation subject, fully considered the differences in the use of different types of energy in the same project, and calculate the affordable price of natural gas for use in a given application with the same effect as using alternative energy. When using natural gas, users of any type can choose the most competitive alternative energy to replace natural gas. Therefore, the alternative energy price method is the most widely used method for all types of users to calculate affordable natural gas prices.

\section{B. Net Return Value Method}

When the project investment, operation cost and product price are known, the upper limit of natural gas price can be deduced by using the method of economic evaluation to get the expected benefit target (such as the internal rate of return of the enterprise reaching the benchmark rate of return of the industry). In this regard, Hong Bo et al. [6] put forward the "asset pricing method", pointing out that "in the case of longterm use of natural gas through a large amount of investment, the capital cost of investment must be considered to comprehensively evaluate the value of natural gas market", according to the product price to reverse the expected return of the natural gas price Enterprises can bear the price of natural gas. Subsequently, Li Luguang [7,16-17] put forward the "net return value method", that is, "according to the theory of equilibrium value and the principle of marginal contribution, the economic value of natural gas use can be calculated by the price of the final product of natural gas use and output and the cost of input factors of production, etc." Both "asset pricing method" and "net return value method" are based on the price of enterprise products and input factors of production to deduce the affordable price of natural gas, which should be classified into the same method, that is, net return value method. The net return method is applicable to natural gas users who produce marketable products from natural gas as raw materials or fuels. The price of products is entirely determined by market competition mechanism and the cost of products can be clearly calculated.

\section{Statistical Analysis Method}

According to the equilibrium value theory and marginal contribution theory, Li Luguang $[7,16]$ put forward the statistical analysis method to calculate the affordable natural gas price through the relevant economic indicators submitted by industrial enterprises to the government statistical department. Statistical analysis is applicable to the production of marketable products, and the price of products is entirely formed by market competition mechanism. However, the variety and specifications of products of enterprises are diverse, and each product is not independently costed for natural gas purposes.

\section{Expenditure Limit Method}

For urban residents, Hao Yu et al. [5], Hong Bo et al. [6], Zhao Lianzheng [18] put forward the expenditure limit method, that is, to set the expenditure of resident gas does not exceed a certain proportion of per capita disposable income to evaluate the affordability of natural gas prices. Y.X.HE et al. [19] According to the level of per capita disposable income, residents are divided into five groups: low income, middle and low income, middle and high income, and high income. Expenditure quota method is mainly used to study the affordability of natural gas price of residents. The affordable natural gas price is calculated according to the ratio coefficient of resident gas expenditure to per capita disposable income. For this ratio coefficient, there are great differences in the research process between different literatures, and the values are between $0.74 \%$ and $5 \%$ [5-6, 8-10, 18-19].

\section{E. Input-output Method}

Zhou Zhibin [20] use input-output analysis method stablished the relationship between the various sectors of the national economy. On this basis, according to the principle of maximizing the profits of enterprises, the bearing capacity of various industries on the price of natural gas is measured. At the same time, starting from the analysis of the expenditure structure of residents, the sum of residents' natural gas expenditure in the total expenditure of residents is determined. According to the principle of maximizing the utility of residents, the affordability of natural gas prices in various industries is determined.

\section{THEORETICAL APPLICATION AND DEVELOPMENT OF NATURAL GAS PRICE AFFORDABILITY IN CHINA}

\section{A. Theoretical Application of Natural Gas Price Affordability}

Based on the basic method of affordable natural gas price calculation, Chinese scholars have studied the affordability of natural gas price of users in various regions and industries. By comparing the natural gas prices affordable to different types of users, scholars generally believe that the affordability of different users is different: the affordability of urban gas users is higher, the influence of alternative energy prices and the product market of the project on industrial fuel users is quite different, and the natural gas chemical users and natural gas power generation are different. User gas price affordability is weak [8-11,21].

In view of the differences in gas price bearing capacity of different users in China, scholars have proposed that the reform of pricing mechanism of natural gas should be accelerated, the law of supply and demand in the market should be fully considered, the natural gas market should be improved, the price of natural gas should be set differently according to the principle of high quality and high price, and the price of natural gas should be properly raised for users with high gas price bearing capacity. Give full play to the due role of natural gas in the national economy and people's livelihood, and make full use of natural gas resources by formulating reasonable natural gas utilization policies and gradually rationalizing natural gas prices. In addition, China should actively promote the process of market-oriented pricing of natural gas, vigorously adjust the 
price of natural gas, gradually narrow the gap between the actual price and the theoretical price, and establish and improve the price linkage mechanism of natural gas and alternative energy [22].

\section{B. Affordable Natural Gas Prices}

The affordable natural gas price is determined by other factors besides economic factors: $\mathrm{Wu}$ Yongping [23] considers that economic and environmental benefits of natural gas instead of coal should not be separated when researching whether natural gas should replace coal. Wang Fuping [24] thinks that in order to evaluate the value of urban natural gas heating, we should consider not only the economic value, but also the environmental value.

\section{Natural Gas Market Demand Curve}

According to the fundamentals of microeconomics [25], "the highest price a person is willing to pay is usually considered his or her reserve price. The retention price is the highest price that anyone is willing to accept and purchase. " Taking the market price as the vertical axis and the consumption as the horizontal axis, and sorting different consumers according to the reserve price from high to low, a curve can be drawn, which is the demand curve. According to the definition of affordable natural gas price, the affordable natural gas price, i.e. the reserve price of each natural gas user, can be ranked from high to low according to the affordable natural gas price of different natural gas users, and a curve can be formed, which is the demand curve of natural gas market. Zhao Lianzheng [18], He Runmin [26] combined with the calculation method of affordable natural gas price and the spatial forecast of natural gas user demand, drawn the demand curves of natural gas market in China, and established the relationship between natural gas price and demand.

\section{Price Equilibrium Theory}

He Runmin [26] and Bai Lanjun [27] proposed to draw the demand curve of natural gas market based on the calculation method of affordable natural gas price and the spatial forecast of natural gas user demand. According to the supply volume and price of natural gas, the supply curve of natural gas was drawn. The focus of demand curve and supply curve was taken as equilibrium point, and the corresponding sales volume was made. For the balance of supply and demand, the corresponding price is the equilibrium price of natural gas. In the perfectly competitive market, the equilibrium point of the industry market price is determined by the intersection of the demand curve and the supply curve, but there is no supply curve in the imperfectly competitive market [28]. The equilibrium price is different from that in the perfectly competitive market.

\section{PROSPECT OF RESEARCH ON NATURAL GAS PRICE BEARING CAPACITY}

Through a systematic review of the theory of energy price bearing capacity at home and abroad, it can be seen that great progress has been made in domestic research, and a preliminary theoretical system of natural gas price bearing capacity has been formed. (1) To study the generalized affordable natural gas price and identify the various noneconomic factors that affect the affordable natural gas price of users and their quantitative methods. (2) Based on the demand curve of natural gas market and the basic principle of market affordable natural gas price, combined with the current pricing mechanism of natural gas in China, this paper quantitatively studies the impact of alternative energy price, natural gas utilization policy, natural gas demand space and other factors on the natural gas market. (3) Continue to explore the price equilibrium under the incomplete competition of China's natural gas market, and study the price formation mechanism of China's natural gas market combining with the reform process of China's natural gas market.

\section{REFERENCES}

[1] L.J. Bai, "A discussion on gas pricing in a market economy," International Petroleum Economics, vol. 8(6), pp. 18-59, 2000.

[2] L.J. Bai, "Gas pricing in a market economy," Natural Gas Technology and Economy, vol. 8(6), pp.18-59, 2000.

[3] West - East Gas Price Research Group. Natural gas industry pricing, Beijing: Petroleum Industry Press, 2003, pp. 87-89.

[4] G.L. Wang, M.C. Zhou, and Y.M. Jia, et al.Research and practice of natural gas pricing, Beijing: Petroleum Industry Press, 2007, pp. 44-48.

[5] Y. Hao, W.H. Cao, and L.Z. Zhao, "An approach to natural gas market value for city gas," Petroleum Planning \& Engineering, vol. 20(3), pp. 11-13, 2009.

[6] B. Hong, L.Z. Zhao, and Y. Hao, "Market valuation of natural gas in China," International Petroleum Economics, vol. 18(6), pp. 11-19, 2010.

[7] L.G. Li, Z.B. Zhou, and J.G. Kang, et al. Study on calculation methods of economic value from natural gas as an energy source, Beijing: Science Press, 2012, pp. 5-18.

[8] H.M. Li and W. Li, "Analysis of natural gas demand and affordable price in Yunnan province," Natural Gas Technology, vol. 1(3), pp. 85-87, 2007.

[9] J.P. Yin and G.Q. Song, "Affordability in Shanghai gas markets analysis," Price Theory and Practice, vol. 2011(3), pp. 29-30.

[10] J.P. Yin and X.X. Sun, "The impact of break-even pricing of the imported gas on the gas market in China: A case study," Natural Gas Industry, vol. 35(1), pp. 131-136, 2015.

[11] J.P. Yin and J.L. Zhan, "Study on the price affordability of natural gas users based on energy price comparison - taking Beijing as an example," Price Theory and Practice, vol. 2012(4), pp. 28-29.

[12] Q. Li, Y. Wang, and J.L. Zhou, "Analysis on natural gas price affordability in Shanxi province," Modern Business, vol. 2011(2), pp. 152-154.

[13] Q. Zhao, L. Wang, L. Cui, W.Q. Wang, and G.F. Wang, "Characteristics and economic analysis of natural gas utilization in northeast petrochemical enterprises," Journal of Liaoning Shihua University, vol. 37(3), pp. 70-75, 2017.

[14] J.L. Mou, "Analysis on natural gas price affordability in Beijing," Price Theory and Practice, vol. 2007(5), pp. 35-36.

[15] Y.F. Shi, R.M. He, et al. Study on gas consumption characteristics of natural gas industry users, Beijing: Petroleum Industry Press, 2013, pp. 16-17.

[16] L.G. Li, Z.B. Zhou, J.G. Kang, W.M. Xu, M.K. Liu, “A package of basic calculation methods of economic value from natural gas as an energy source,” Natural Gas Industry, vol. 31(11), pp. 1-5, 2011.

[17] L.G. Li, Z.B. Zhou, J.G. Kang, W.M. Xu, M.K. Liu, Z.A. Jiang. "Calculation of economic values in major usages of natural gas in China: A case study of that in 2009," Natural Gas Industry, vol. 32(3), pp. 1-5, 2012.

[18] L.Z. Zhao, "Research on the market value curve of natural gas[J].Petroleum Planning \& Engineering, vol. 20(1), pp. 1-4, 2009. 
[19] Y.X. He, T. Xia, Y.Y. Liu, L.F. Zhou, and B. Zhou, "Residential natural gas price affordability analysis-A case study of Beijing," Renewable and Sustainable Energy Reviews, 2013(28), pp. 392-399.

[20] Z.B. Zhou, Research and application of natural gas price affordability model. Beijing: China Statistics Press, 2010, pp. 29-39.

21] J.P. Ying and Y.H. Wang, "National residents affordability to natura gas prices," Price Theory and Practice, vol. 2012(6), pp. 47-48.

[22] T. Li and X.Z. Wang, "Research on price of natural gas via alternative energy sources," Technology \& Economics in Petrochemicals, vol. 22(6), pp. 10-13, 2006

[23] Y.P. Wu, B.C. Yu, and F.C. Li, “Assessing the natural gas replacing coal policy(NGRCP) based on a cost -benefit analysis and the economic and environmental benefits of the NGRCP," China Public Administration Review, vol. 16(2), pp.3-13, 2014
[24] F.P. Wang, L. Yan, and F.B. Chen. "Evaluation of city-gas heating value and some suggestions," Natural Gas Technology and Economy, vol. 8(6), pp. 58-60, 2014,.

[25] H.R. Varian, Intermediate Microeconomics: A Modern Approach, Shanghai: Shanghai Sanlian Publishing House, Shanghai People's Publishing House, 2003, pp. 4-7.

[26] R.M. He, Theories and methods of natural gas pricing based on coordinated development between economy and environment, Sichuan: Southwest Petroleum University, 2013, pp. 66-89.

[27] L.J. Bai, Natural gas economics, Beijing: Petroleum Industry Press, 2001, pp. 312-325.

[28] H.Y. Gao, Microeconomics, Beijing: China Renmin Uinversity Press, 2010 , pp. 180 